\title{
Prediction of tumor response of rectal cancer cells via 3D cell culture and in vitro cytotoxicity assay before initiating preoperative chemoradiotherapy
}

\author{
JEONGHYUN KANG $^{1}$, MIN CHUL PARK ${ }^{2}$, JINA KIM $^{2}$, HYUK HUR $^{1}$, BYUNG SOH MIN $^{1}$, \\ SEUNG HYUK BAIK ${ }^{1}$, KANG YOUNG LEE ${ }^{1}$ and NAM KYU KIM ${ }^{1}$ \\ ${ }^{1}$ Department of Surgery, Yonsei University College of Medicine, Seoul 03722; \\ ${ }^{2}$ CureBio Co., Ltd., Suwon, Gyeonggi 16229, Republic of Korea
}

Received November 27, 2018; Accepted July 23, 2019

DOI: $10.3892 / \mathrm{ol} .2019 .10702$

\begin{abstract}
The aim of the present study was to investigate the utility of 3D cell culture and in vitro cytotoxicity assays, performed using cells derived from biopsies obtained prior to the initiation of preoperative chemoradiotherapy (preop-CRT), in predicting tumor response to chemoradiotherapy following preop-CRT in rectal cancer. Biopsies were obtained from 49 patients with locally advanced rectal cancer that underwent preop-CRT between August 2015 and March 2017. Tumor tissue was obtained before initiating preop-CRT. The response to chemoradiation was assessed by in vitro cytotoxicity assay following $3 \mathrm{D}$ cell culture and radiation treatment. The associations between the results from the cytotoxicity assay, and tumor regression grade (TRG) and yp node (ypN) positivity were investigated. Among 49 patients, 26 patients were available for analysis. Cytotoxicity ranged from 25.5-72.6\% (median, $47.6 \%)$. There was no difference in cytotoxicity according to the TRGs $1-5(\mathrm{P}=0.940)$, or good tumor response (TRGs 1-2 vs. TRGs 3-5; $\mathrm{P}=0.729$ ). However, there was a significant difference in cytotoxicity between the ypN-negative and -positive groups (53.2 \pm 14.1 and 38.7 \pm 10.1 , respectively; $\mathrm{P}=0.021$ ). Following dichotomization of patients with $45 \%$ cut-off value, the cytotoxicity assay was the only factor that predicted ypN positivity in multivariate analysis (odds ratio, 13; $95 \%$ confidence interval, 1.2-133.2; $\mathrm{P}=0.031$ ). In conclusion, the cytotoxicity assay using the $3 \mathrm{D}$ cell culture method can be used to predict tumor response, particularly ypN positivity, in patients with rectal cancer who are scheduled for preop-CRT.
\end{abstract}

Correspondence to: Professor Nam Kyu Kim, Department of Surgery, Yonsei University College of Medicine, 50 Yonsei-ro, Seodaemun, Seoul 03722, Republic of Korea

E-mail:namkyuk@yuhs.ac

Key words: rectal cancer, 3D cell culture, cytotoxicity assay, tumor regression grade, pathologic complete response

\section{Introduction}

Preoperative chemoradiotherapy (preop-CRT) is considered as the standard treatment option for locally advanced rectal cancer (1). Following reports on the favorable long-term oncological outcome of patients with pathologic complete response (pCR) (2-4), investigation into potentially useful clinicopathological factors for predicting pCR was conducted, with various factors proposed to be associated with pCR $(5,6)$. Delaying surgery for patients who presented with good clinical outcomes has gained popularity recently $(7,8)$. It was reported that following preop-CRT in rectal cancer, persistent lymph node metastasis (LNM) was the most indicative factor of poor prognosis $(9,10)$. In addition, yp node $(\mathrm{ypN})$ positivity (metastatic lymph node detection after surgery) was revealed to be the most important prognostic factor to predict the survival of patients harboring no residual tumor (ypT0) following surgical resection (2). There is still some controversy regarding this topic, and one of the main concerns with delaying the surgery or the local excision approach is the difficulty of predicting LNM even in the case of good clinical response. Swellengrebel et al (11) reported that $28.5 \%$ of patients with no residual tumor in the rectal wall had persistent regional LNM and $41 \%$ of near-complete response patients had ypT3 stage. Although several researchers have investigated predictors of ypN-positive status following preop-CRT, the studies are limited, as the factors used in the nomograms are often difficult to obtain prior to radical resections (12-14). Considering the low predictive rate of the current imaging techniques for restaging LNM $(15,16)$, novel strategies to predict LNM more accurately following preop-CRT are still warranted.

The 3D cell culture system has been widely used, as cells in 3D environments may be more similar to cells in living organisms (in vivo) compared to the flat, unnaturally thin and single-layer cells grown in 2D environments (17). Typical cells in 3D systems are ellipsoids with dimensions of 10-30 $\mu \mathrm{m}$; in contrast, cells in 2D are flat with a typical thickness of $3 \mu \mathrm{m}$ (18). With regards to environmental comparison, typical cells in 3D have $\sim 100 \%$ of their surface area exposed to other cells or matrix, whereas cells in $2 \mathrm{D}$ have $\sim 50 \%$ of their surface area exposed to fluid, $\sim 50 \%$ exposed to the flat culture 
surface or intermediate, and very little surface area exposed to other cells. A previous data analysis of spheroid-based drug screening systems revealed that tumor spheroid size and morphology in a 3D culture system was associated with in vivo drug sensitivity (19). Previous studies demonstrated significantly increased resistance to radiation in tumor cells in $3 \mathrm{D}$ cell culture, in comparison with that of $2 \mathrm{D}$ culture $(20,21)$. Storch et al (21) reported increased levels of heterochromatin in $3 \mathrm{D}$ cell cultures that led to increased survival, and a decreased number of DNA double-strand breaks and lethal chromosome aberrations in response to radiation, compared with those in monolayer cell cultures. These data suggest potential clinical benefits of 3D cell culture for predicting tumor responses to radiation. Nevertheless, the predictive potential of 3D cell culture and cytotoxicity analysis has not been widely assessed in patients with rectal cancer who have undergone preop-CRT.

Thus, the aim of the present study was to evaluate the clinical potential of the 3D cell culture method for predicting tumor response to preoperative chemoradiotherapy in patients with rectal cancer.

\section{Materials and methods}

Patient enrolment. A total of 49 individuals (29 males, aged 22-82 years) suffering from locally advanced rectal cancer that underwent preop-CRT were prospectively enrolled at the Severance Hospital, Yonsei University College of Medicine (Seoul, Republic of Korea) between August 2015 and March 2017. Patients with histopathologically confirmed adenocarcinoma of the rectum at clinical stage II or III were enrolled for the present study (22). All enrolled patients underwent preoperative biopsy, for the cytotoxicity assay, prior to the initiation of preop-CRT. The protocol used for the preop-CRT was described in previous studies $(23,24)$. Briefly, the preoperative radiation therapy consisted of a total dose of 45 Gy in 25 fractions delivered to the pelvis, followed by a $5.4 \mathrm{~Gy}$ boost to the primary tumor, over a period of 5 weeks (1.8 Gy for 5 days). The pelvic radiation volume was as follows: The superior border $1.5 \mathrm{~cm}$ above the sacral promontory (L5 level); the inferior border at the inferior margin of the obturator foramen or $3 \mathrm{~cm}$ below the lower tumor margin; the lateral border $1.5 \mathrm{~cm}$ lateral to the bony pelvis; the anterior border $3 \mathrm{~cm}$ anterior to the tumor; and the posterior border $0.5 \mathrm{~cm}$ posterior to the sacral surface. The prescription dose was specified at the isocenter; the three-field treatment plan comprised a 6-MV photon posterior-anterior field and 6- or 10-MV photon opposed lateral fields with wedges of $45^{\circ}$. For the boost treatment, five ports were used. Intravenous bolus injections of 5-fluorouracil/leucovorin $\left(425 / 20 \mathrm{mg} / \mathrm{m}^{2}\right.$ once per day during weeks 1 and 5) or capecitabine $\left(825 \mathrm{mg} / \mathrm{m}^{2}\right.$, twice daily during the radiation therapy period) were administered to the patients during preop-CRT. Total mesorectal excision (TME) was performed 6-12 weeks after the completion of preop-CRT. The protocol of the present study was approved by the institutional review board of the Severance Hospital, Yonsei University College of Medicine (Seoul, Republic of Korea) (approval no. 4-2011-0445). Written informed consent was obtained from all participants.

\section{$3 D$ cell culture}

Tissue harvest. Tissue was collected prior the initiation of preop-CRT using rigid sigmoidoscopy and forceps biopsy. The tissues were placed into $25-\mathrm{cm}^{2}$ flasks, filled with RPMI culture medium supplemented with $1 \%$ penicillin-streptomycin HyClone; GE Healthcare Life Sciences). Before tissue dissociation, harvested tissues were maintained at $37^{\circ} \mathrm{C}$ in a $5 \% \mathrm{CO}_{2}$ incubator.

Cancer tissue dissociation and $2 D$ culture. Following the removal of media from the $25-\mathrm{cm}^{2}$ flasks, the tissue samples were transferred to $1.5-\mathrm{ml}$ micro tubes, and the weight was measured. The samples were subsequently transferred to $60-\mathrm{mm}^{2}$ dishes filled with $5 \mathrm{ml}$ RPMI culture medium supplemented with $1 \%$ penicillin-streptomycin and washed by pipetting; this procedure was repeated twice. The tissue was then transferred to $60-\mathrm{mm}^{2}$ dishes filled with $5 \mathrm{ml}$ trypsin EDTA (HyClone; GE Healthcare Life Sciences), cut into smaller pieces using a blade (Nopa Instruments), and incubated for $20 \mathrm{~min}$ at $37^{\circ} \mathrm{C}$ in a $5 \% \mathrm{CO}_{2}$ incubator. Subsequently, the tissue was harvested using $5 \mathrm{ml}$ RPMI medium supplemented with $1 \%$ penicillin-streptomycin and $10 \%$ FBS (HyClone; GE Healthcare Life Sciences), transferred to 15-ml conical tubes, and the solution was centrifuged at $260 \mathrm{~g}$ for $2 \mathrm{~min}$ at room temperature. The supernatant was removed, and the pellets were resuspended in $10 \mathrm{ml}$ RPMI supplemented with $1 \%$ penicillin-streptomycin and $10 \% \mathrm{FBS}$, followed by transferring the tissues to $100-\mathrm{mm}^{2} 2 \mathrm{D}$ culture dishes (Thermo Fisher Scientific, Inc.) and incubating at $37^{\circ} \mathrm{C}$ for $2-3$ days.

Cancer cell $3 D$ culture. Cells were harvested by pipetting and transferred to $15-\mathrm{ml}$ conical tubes. The tissue was then transferred to $60-\mathrm{mm}^{2}$ dishes filled with $5 \mathrm{ml}$ trypsin EDTA (HyClone; GE Healthcare Life Sciences), cut into smaller pieces using a blade (Nopa Instruments Medizintechnik $\mathrm{GmbH}$ ), and incubated for $20 \mathrm{~min}$ at $37^{\circ} \mathrm{C}$ in a $5 \% \mathrm{CO}_{2}$ incubator. Subsequently, the tissue was harvested using $5 \mathrm{ml}$ RPMI medium supplemented with $1 \%$ penicillin-streptomycin and 10\% FBS (HyClone; GE Healthcare Life Sciences), transferred to $15-\mathrm{ml}$ conical tubes, and the solution was centrifuged at $260 \mathrm{~g}$ for $2 \mathrm{~min}$ at room temperature. The 2D-cultured cells were detached using Accumax (EMD Millipore). The dissociated cells were counted using a C-Chip disposable hemocytometer (INCYTO). The cells were diluted in $1 \mathrm{ml}$ RPMI medium supplemented with $1 \%$ penicillin-streptomycin and $10 \%$ FBS to a concentration of 5,000 cells $/ 100 \mu \mathrm{l}$ and seeded onto ultra-low attachment 96-well 3D-culture plates (Corning Inc.).

Radiation treatment. Defining the day on which the cells were reseeded for 3D culture as day 0 , the 3D-cultured cells were treated with 5 Gy radiation at day 3 (Gammacell low dose-rate irradiator; Nordion, Inc.). The control group did not receive any radiation. The cultured cells were incubated at $37^{\circ} \mathrm{C}$ for 2 days.

Imaging before and after radiation treatment. Images of 3D-cultured cells before and 2 days after radiation treatment were acquired by Cell Scanner (MBD), equipped with a $\mathrm{x} 4$ objective lens. The cells and culture media were transferred to $1.5-\mathrm{ml}$ tubes, and centrifuged at $95 \mathrm{~g}$ for $2 \mathrm{~min}$. The supernatant and pellets in each tube were stored at $-20^{\circ} \mathrm{C}$. 


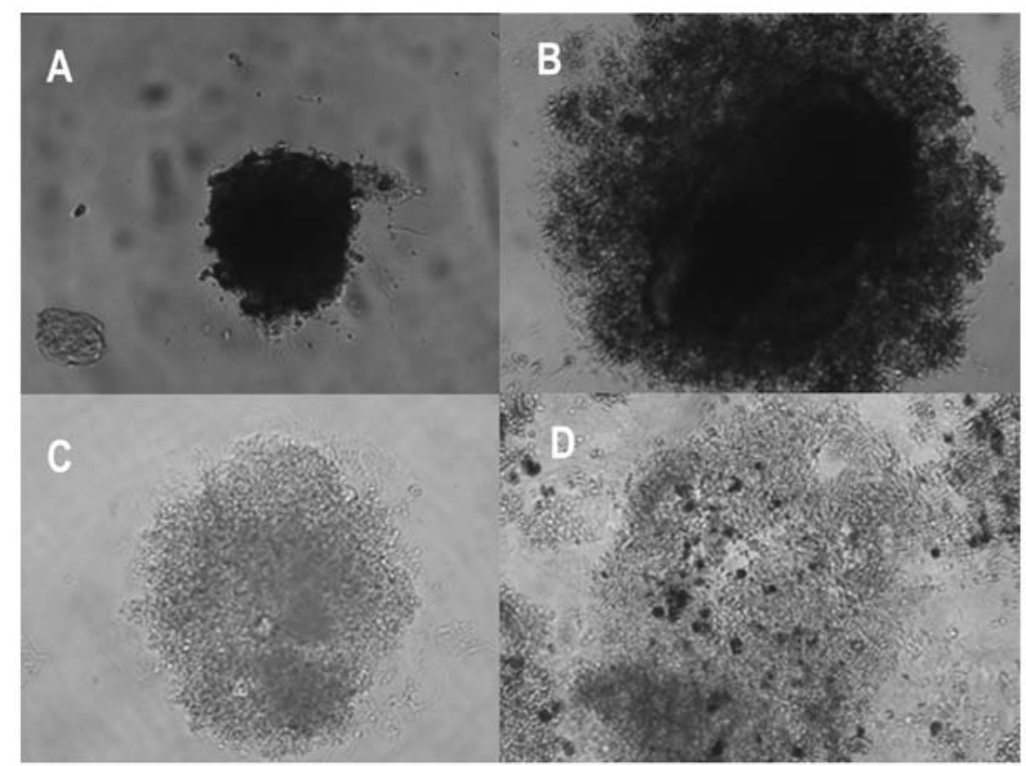

Figure 1. Four types of morphology of 3D spheroids formed in 3D cell cultures. The 3D spheroids formed by 3D cell culture of rectal cancer tissues, obtained before preoperative chemoradiotherapy, were grouped as (A) 'round', (B) 'mass', (C) 'aggregate' and (D) 'none' types.

\section{Evaluation of $3 D$ cell culture}

Morphological classification. Morphological assessment and classification were performed prior to radiation treatment. The resulting spheroids were classified into four distinct groups based on morphology as 'round', 'mass', 'aggregate' and 'none' (Fig. 1) (19). For further analysis, the 'round', 'mass', and 'aggregate' types were grouped into the category 'mass-forming group' for efficient statistical analysis. The morphological classification was completed by an independent researcher, who was unaware of the patients' clinicopathological outcomes.

Cytotoxicity analysis. Defining the day on which the cells were reseeded for 3D culture as day 0 , the culture medium was harvested and lactate dehydrogenase (LDH) enzyme activity was determined to check cytotoxicity levels at day 5 ( 2 days of additional incubation following radiation treatment). The cells were separated from the harvested media by centrifugation at $1,000 \mathrm{~g}$ for $15 \mathrm{~min}$ at room temperature. The supernatant was collected and the LDH enzyme activity was measured using an LDH-cytotoxicity assay kit (BioVision, Inc.) following the manufacturer's protocol. In order to calculate the ratio between LDH enzyme activity in the media and cells, the total cellular LDH enzyme activity from the cells was also measured.

Measurements of endoscopy and magnetic resonance imaging (MRI) parameters. All patients underwent endoscopies from 4-6 weeks following completion of preop-CRT. All endoscopic regression grading was estimated by endoscopists. Endoscopic grading was classified into endoscopy_CR (normal mucosa, whitish scar only), endoscopy_near CR $(<1 \mathrm{~cm}$ ulcer without remaining visible tumor), and endoscopy_non $\mathrm{CR}$ (ulcer $>1 \mathrm{~cm}$ without remaining visible tumor, remaining mass regardless of ulcer).

Patients underwent two stages of MRI examinations. The first examination was performed before the initiation of preop-CRT (pre-CRT MRI) and the MRI second was performed from 4-6 weeks following the completion of preop-CRT (post-CRT MRI). A 3.0 T scanner [(Magnetom Tim Trio; Siemens Medical Solutions) or (Ingenia; Philips Medical Systems)] was used for pre- and post-CRT MRI examinations. In the present study, magnetic resonance (MR) tumor regression grade (TRG), diffusion-weighted image (DWI) and MR tumor volume reduction rate (TVRR) were evaluated and recorded for each enrolled patient. These MRI-based parameters were evaluated based on protocols from previous studies $(23,25,26)$.

Tumor response assessment following preop-CRT. The Mandard's classifications were used to evaluate TRG (27). pCR was defined as no viable tumor cells in the rectal wall along with no LNM. According to the TRG classification, TRG 1 and TRG 2 were classified as 'good tumor response', while TRG 3-5 were classified as 'poor tumor response'. With respect to tumor downstaging, $T$ downstaging was defined as smaller pathologic ypT compared with clinical $\mathrm{T}$ stage, and $\mathrm{N}$ downstaging was defined as conversion of clinically positive lymph nodes to pathologically negative status.

Statistical analysis. All statistical analyses were performed using SPSS version 23.0 (IBM Corp.). Categorical variables were analyzed using the $\chi^{2}$ test or Fisher's exact test, and continuous variables were analyzed using Student's t-test or ANOVA. Receiver operating characteristic (ROC) curve analysis was used to compare the diagnostic performance of the parameter for predicting ypN positivity. The cut-off values for the variables that provided the best classification between the groups were determined. Factors associated with ypN positivity were analyzed by logistic regression analysis with forward stepwise selection of variables. All variables with $\mathrm{P}<0.2$ on univariate analysis were initially entered into the multivariate analysis. $\mathrm{P}<0.05$ was considered statistically significant. 
Table I. Comparison of clinicopathological factors according to the success or failure of patients that were included in the cytotoxicity assay.

\begin{tabular}{|c|c|c|c|}
\hline Clinicopathological factor & Success group $(\mathrm{n}=26), \mathrm{n}(\%)$ & Failure group $(\mathrm{n}=23), \mathrm{n}(\%)$ & P-value \\
\hline Sex & & & 0.562 \\
\hline Male & $14(53.8)$ & $15(65.2)$ & \\
\hline Female & $12(46.2)$ & $8(34.8)$ & \\
\hline Age, years & & & 0.332 \\
\hline$<65$ & $21(80.8)$ & $15(65.2)$ & \\
\hline$\geq 65$ & $5(19.2)$ & $8(34.8)$ & \\
\hline $\mathrm{BMI}, \mathrm{kg} / \mathrm{m}^{2}$ & $24.1 \pm 3.7^{\mathrm{a}}$ & $22.8 \pm 2.6^{\mathrm{a}}$ & 0.167 \\
\hline Distance from anal verge, $\mathrm{cm}$ & $6.2 \pm 2.1^{\mathrm{a}}$ & $5.9 \pm 2.3^{\mathrm{a}}$ & 0.661 \\
\hline Tumor location & & & 0.394 \\
\hline Low $(<5 \mathrm{~cm})$ & $9(34.6)$ & $11(47.8)$ & \\
\hline Middle $(5-10 \mathrm{~cm})$ & $17(65.4)$ & $12(52.2)$ & \\
\hline CEA (initial), $\mu \mathrm{g} / 1$ & $6.0 \pm 7.4^{\mathrm{a}}$ & $6.5 \pm 7.5^{\mathrm{a}}$ & 0.796 \\
\hline cT stage & & & $0.286^{\mathrm{c}}$ \\
\hline cT2 & 0 & $2(8.7)$ & \\
\hline cT3 & $23(88.5)$ & $20(87)$ & \\
\hline cT4 & $3(11.5)$ & $1(4.3)$ & \\
\hline $\mathrm{cN}$ stage & & & $0.4^{\mathrm{c}}$ \\
\hline Node-negative & $2(7.7)$ & $4(17.4)$ & \\
\hline Node-positive & $24(92.3)$ & $19(82.6)$ & \\
\hline Cytotoxicity, \% (range) & $47.6^{\mathrm{b}}(25.5-72.6)$ & N/A & \\
\hline
\end{tabular}

${ }^{a}$ Mean \pm standard deviation. ${ }^{b}$ Median. ${ }^{~}$ Fisher's exact test. BMI, body mass index; CEA, carcinoembryonic antigen; N/A, not available; cT, clinical tumor; cN, clinical node.

Table II. Association of cytotoxicity assay with 3D morphologic classification before radiation.

\begin{tabular}{lcc}
\hline Parameters & $\mathrm{n}=26, \mathrm{n}(\%)$ & Cytotoxicity, mean \pm SD \\
\hline 3D morphologic classification' & & $0.490^{\mathrm{c}}$ \\
Round & $1(3.8)$ & 50.9 \\
Mass & $3(11.5)$ & $51.2 \pm 10.7$ \\
Aggregate & $15(57.7)$ & $52.4 \pm 16.8$ \\
None & $7(26.9)$ & $41.9 \pm 9.3$ \\
Subgroup analysis & & $52.1 \pm 15.3$ \\
'Mass-forming group'b & $19(73)$ & $41.9 \pm 9.3$ \\
'None group' & $7(26.9)$ & 0.113 \\
\hline
\end{tabular}

a3D morphologic classification was analyzed before radiation treatment. 'Morphologic classification of 'round', 'mass' and 'aggregate' were classified into 'mass forming' group and 'none' was classified into the 'none' group. 'Analyzed by ANOVA test.

\section{Results}

A total of 49 patients were initially enrolled in the present study for performing a cytotoxicity assay on 3D-cultured cells exposed to radiation. Finally, the results from 26 patients $(53 \%)$ were available for further analysis. The reasons for failure in obtaining results from the remaining patients comprised cell culture contamination for $15(65 \%)$ patients and insufficient specimens from the biopsy for $8(35 \%)$ patients. There was no difference in clinicopathological characteristics between the success group $(n=26)$ and the failure group $(n=23$; Table I). Among the 26 patients included in the final analysis, cytotoxicity ranged from 25.5-72.6\% (median, 47.6\%).

By morphologic classifications, the 'aggregate' type was the most common (57.7\%), followed by the 'none' type (26.9\%). Mean and the standard deviation of cytotoxicity were 50.9 in 'round' type, $51.2 \pm 10.7$ in mass type, $52.4 \pm 16.8$ in aggregate type and $41.9 \pm 9.3$ in none type respectively. With respect to 
Table III. Association of cytotoxicity with pathologic tumor response.

\begin{tabular}{|c|c|c|c|}
\hline Parameters & $\mathrm{N}$ & $\begin{array}{l}\text { Cytotoxicity, } \\
\text { mean } \pm \text { SD }\end{array}$ & P-value \\
\hline TRG grade & & & $0.940^{\mathrm{a}}$ \\
\hline 1 & 6 & $50 \pm 18.6$ & \\
\hline 2 & 4 & $45.2 \pm 8.9$ & \\
\hline 3 & 11 & $50.8 \pm 12.8$ & \\
\hline 4 & 5 & $48.8 \pm 19.8$ & \\
\hline 5 & 0 & & \\
\hline TRG response & & & 0.729 \\
\hline TRG 1-2 & 10 & $48.1 \pm 15$ & \\
\hline TRG 3-5 & 16 & $50.1 \pm 14.6$ & \\
\hline $\mathrm{pCR}$ & & & 0.909 \\
\hline Yes & 6 & $50 \pm 18.6$ & \\
\hline No & 20 & $49.2 \pm 3.6$ & \\
\hline T downstaging & & & 0.199 \\
\hline Positive & 16 & $52.3 \pm 14$ & \\
\hline Negative & 10 & $44.6 \pm 14.7$ & \\
\hline $\mathrm{N}$ downstaging & & & 0.096 \\
\hline Positive & 17 & $52.8 \pm 14.3$ & \\
\hline Negative & 9 & $42.8 \pm 13.2$ & \\
\hline yp T stage & & & $0.895^{\mathrm{a}}$ \\
\hline 0 & 6 & $50 \pm 18.6$ & \\
\hline 1 & 1 & 53.8 & \\
\hline 2 & 8 & $51.8 \pm 11.5$ & \\
\hline 3 & 11 & $46.8 \pm 15.7$ & \\
\hline yp N stage & & & 0.021 \\
\hline Node-negative & 19 & $53.2 \pm 14.1$ & \\
\hline Node-positive & 7 & $38.7 \pm 10.1$ & \\
\hline
\end{tabular}

${ }^{\mathrm{a} A n a l y z e d ~ b y ~ A N O V A ~ t e s t . ~ T R G, ~ t u m o r ~ r e g r e s s i o n ~ g r a d e ; ~ p C R, ~}$ pathologic complete response; $\mathrm{T}$, tumor; $\mathrm{N}$, node.

associations between cytotoxicity and 3D morphologic classification, there were no differences in cytotoxicity among the 4 groups. Following the grouping of the 'round', 'mass' and 'aggregate' types into the 'mass-forming' group, there were no differences in the cytotoxicity between the 'mass-forming group' and the 'none group' (Table II).

With respect to the association between cytotoxicity and pathologic tumor response (Table III), there was no difference in cytotoxicity based on either the TRGs $1-5,(\mathrm{P}=0.940)$ or good tumor response (TRGs $1-2$ vs. TRGs $3-5$; $\mathrm{P}=0.729$ ). There was a weak association between cytotoxicity and $\mathrm{N}$ downstaging status $(52.8 \pm 14.3$ in the $\mathrm{N}$ downstaging-positive group vs. $42.8 \pm 13.2$ in the $\mathrm{N}$ downstaging-negative group; $\mathrm{P}=0.096$ ). In contrast, there was a significant difference in cytotoxicity between the ypN-positive and the ypN-negative groups $(53.2 \pm 14.1$ vs. $38.7 \pm 10.1$, respectively; $\mathrm{P}=0.021)$.

The morphological classifications were associated with pathologic tumor response. The rate of $\mathrm{T}$ downstaging was marginally higher in the 'mass-forming group' compared to that of the 'none group' $(73.7 \%$ vs. $28.6 \%$, respectively; $\mathrm{P}=0.069)$. Although the $\mathrm{ypN}$-positive rate was lower in the 'mass-forming group' (15.8\%) compared with that in the 'none group' $(57.1 \%)$, the difference was not statistically significant $(\mathrm{P}=0.057$; Table IV). The ROC curves were generated for cytotoxicity in patients with ypN-positive status and the area under the curve was 0.801 . Using the ROC curves, the Youden's index was calculated to be 45.05 (Fig. 2).

Using the Youden's index value as the cut-off value, the patients were dichotomized into low-cytotoxicity and high-cytotoxicity groups. There were no differences in the clinicopathological and radiological parameters between the high-and low-cytotoxicity groups, except for the ypN-positivity (Table V). The high-cytotoxicity group showed significantly lower ypN-positivity (7.1\%) than that of the low-cytotoxicity group (50\%; $\mathrm{P}=0.026)$.

3D morphologic classification and cytotoxicity assay data were considered in the final multivariate analysis to predict the ypN-positivity (Table VI). The cytotoxicity (dichotomized as low vs. high) was the only factor that predicted ypN-positivity in the multivariate analysis (high-cytotoxicity vs. low-cytotoxicity; odds ratio, 13; 95\% confidence interval, 1.2-133.2; $\mathrm{P}=0.031$ )

\section{Discussion}

The present study demonstrated that the cytotoxicity assay, using $3 \mathrm{D}$ cell culture with radiation, could be a novel alternative for predicting lymph node positivity following preop-CRT in rectal cancer.

Increasing evidence has suggested that good tumor response following preop-CRT may warrant a decrease in radical resection and promotion of an approach that involves either delaying the surgery or local excision $(28,29)$. However, the basic prerequisite for these approaches is no or minimal possibility of regional LNM. Accurate preoperative assessment of LNM is crucial for effectively employing the delay in surgery or radical resection approaches in patients suspected of clinical complete response. Nevertheless, it was reported that current imaging tools have low sensitivity or specificity for defining LNM following preop-CRT (15). The reliability of imaging techniques for evaluating lymph node positivity following preop-CRT in rectal cancer is known to be poor, and there are no standard guidelines to define lymph node positivity (30).

In order to overcome these inherent limitations of imaging-based detection of lymph node positivity following preop-CRT, a clinical outcome-based prediction model was introduced. Jwa et al (12) reported that patient age, ypT stage, tumor differentiation, clinical $\mathrm{N}$ stage, lymphovascular invasion (LVI) and perineural invasion (PNI) could reliably predict LNM following preop-CRT. A nomogram using these parameters was developed and showed high similarity between nomogram-predicted and real lymph node positivity following preop-CRT. Although the nomogram was based on a relatively large and homogeneously treated patient group from a single center, this nomogram included pathological parameters such as ypT stage, LVI and PNI that can be more accurately derived from resected rectum, following definite TME, compared to preoperative biopsy specimens. The use of this nomogram 
Table IV. Association of 3D morphologic classification with pathologic tumor response.

\begin{tabular}{|c|c|c|c|c|}
\hline Parameters & $\mathrm{N}$ & Mass-forming group $(n=19), n(\%)$ & None group $(\mathrm{n}=7), \mathrm{n}(\%)$ & P-value \\
\hline TRG grade & & & & $0.292^{\mathrm{a}}$ \\
\hline 1 & 6 & $6(31.6)$ & 0 & \\
\hline 2 & 4 & $2(10.5)$ & $2(28.6)$ & \\
\hline 3 & 11 & $7(36.8)$ & $4(57.1)$ & \\
\hline 4 & 5 & $4(21.1)$ & $1(14.3)$ & \\
\hline 5 & 0 & 0 & 0 & \\
\hline TRG response & & & & $0.668^{\mathrm{a}}$ \\
\hline TRG 1-2 & 10 & $8(42.1)$ & $2(28.6)$ & \\
\hline TRG 3-5 & 16 & $11(57.9)$ & $5(71.4)$ & \\
\hline $\mathrm{pCR}$ & & & & $0.146^{\mathrm{a}}$ \\
\hline Yes & 6 & $6(31.6)$ & 0 & \\
\hline No & 20 & $13(68.4)$ & 7 (100) & \\
\hline $\mathrm{T}$ downstaging & & & & $0.069^{\mathrm{a}}$ \\
\hline Positive & 16 & $14(73.7)$ & $2(28.6)$ & \\
\hline Negative & 10 & $5(26.3)$ & $5(71.4)$ & \\
\hline $\mathrm{N}$ downstaging & & & & 0.188 \\
\hline Positive & 17 & $14(73.7)$ & $3(42.9)$ & \\
\hline Negative & 9 & $5(26.3)$ & $4(57.1)$ & \\
\hline yp T stage & & & & $0.252^{\mathrm{a}}$ \\
\hline 0 & 6 & $6(31.6)$ & 0 & \\
\hline 1 & 1 & $1(5.3)$ & 0 & \\
\hline 2 & 8 & $6(31.6)$ & $2(28.6)$ & \\
\hline 3 & 11 & $6(31.6)$ & $5(71.4)$ & \\
\hline yp N stage & & & & $0.057^{\mathrm{a}}$ \\
\hline Node-negative & 19 & $16(84.2)$ & $3(42.9)$ & \\
\hline Node-positive & 7 & $3(15.8)$ & $4(57.1)$ & \\
\hline
\end{tabular}

aFisher's exact test. TRG, tumor regression grade; pCR, pathologic complete response; T, tumor; N, node.

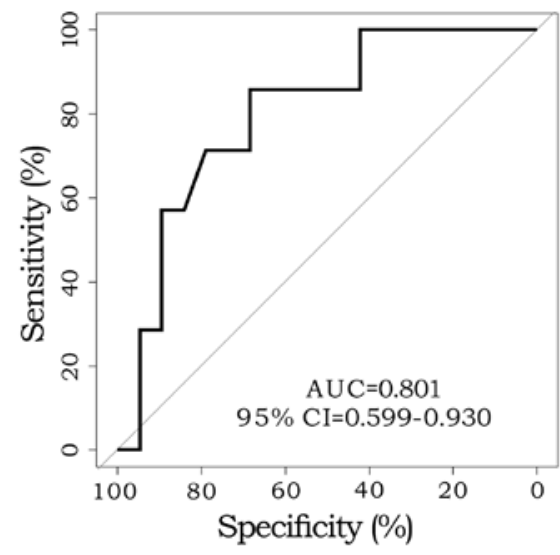

Figure 2. Receiver-operating characteristic curve of 3D cell culture cytotoxicity following radiation and yp node positivity following surgery. The AUC was 0.801 (95\% CI, 0.599-0.930). The optimal cut-off point was calculated as $45.05 \%$, according to Youden's index. AUC, area under the curve; CI, confidence interval.

may therefore be limited in deciding on proceeding for radical surgery.
In the present study, a cytotoxicity assay was conducted to predict tumor response following preop-CRT. However, the assay could not predict postoperative pCR or good tumor response (TRGs 1-2). In contrast, low cytotoxicity, dichotomized by a $45 \%$ cut-off in the cytotoxicity assay, was associated with ypN positivity. Notably, most of the well-known possible predictors of pCR, such as endoscopy grade, MR TRG, MR TVRR and MR DWI demonstrated no associations with ypN positivity, which confirms the difficulties in predicting lymph node status using clinical variables. Nevertheless, the underlying mechanism of the association between ypN positivity and the cytotoxicity assay cannot be elucidated from the findings of the present study. It may be associated with the difference between the radiation responses of primary tumors and metastatic lymph nodes, considering the lack of association between the cytotoxicity level and TRG. The current practice of local excision following good clinical response indicated that metastatic lymph nodes may regress at the same level as the primary tumor following preop-CRT, which was supported by the clinical observations $(31,32)$. In contrast, a study reported $28.5 \%$ lymph node positivity in patients who exhibited pCR (ypT0) (11). Moreover, Choi et al (33) demonstrated that lymph 
Table V. Clinicopathological characteristics and magnetic resonance parameters according to the low- and high-cytotoxicity groups.

\begin{tabular}{|c|c|c|c|}
\hline & $\begin{array}{l}\text { Low-cytotoxicity group } \\
\qquad(\leq 45 ; \mathrm{n}=12), \mathrm{n}(\%)\end{array}$ & $\begin{array}{l}\text { High-cytotoxicity group } \\
\qquad(>45 ; \mathrm{n}=14), \mathrm{n}(\%)\end{array}$ & P-value \\
\hline Sex & & & $>0.999$ \\
\hline Male & $6(50)$ & $8(57.1)$ & \\
\hline Female & $6(50)$ & $6(42.9)$ & \\
\hline Age, years & $51.4 \pm 10.8^{\mathrm{a}}$ & $54.9 \pm 16.2^{\mathrm{a}}$ & 0.530 \\
\hline $\mathrm{BMI}, \mathrm{kg} / \mathrm{m}^{2}$ & $23.7 \pm 3.5^{\mathrm{a}}$ & $24.5 \pm 4^{\mathrm{a}}$ & 0.575 \\
\hline Distance from anal verge, $\mathrm{cm}$ & $6.1 \pm 2.1^{\mathrm{a}}$ & $6.2 \pm 2.2^{\mathrm{a}}$ & 0.875 \\
\hline CEA (initial), $\mu \mathrm{g} / 1$ & $6.5 \pm 7^{\mathrm{a}}$ & $5.6 \pm 8^{\mathrm{a}}$ & 0.759 \\
\hline yp T stage & & & $0.933^{\mathrm{a}}$ \\
\hline T0 & $3(25)$ & $3(21.4)$ & \\
\hline $\mathrm{T} 1$ & 0 & $1(7.1)$ & \\
\hline $\mathrm{T} 2$ & $3(25)$ & $5(35.7)$ & \\
\hline $\mathrm{T} 3$ & $6(50)$ & $5(35.7)$ & \\
\hline yp N stage & & & $0.026^{\mathrm{b}}$ \\
\hline Node-negative & $6(50)$ & $13(92.9)$ & \\
\hline Node-positive & $6(50)$ & $1(7.1)$ & \\
\hline $\mathrm{pCR}$ & & & $>0.999^{\mathrm{b}}$ \\
\hline Yes & $3(25)$ & $3(21.4)$ & \\
\hline No & $9(75)$ & $11(78.6)$ & \\
\hline Endoscopy & & & $0.190^{\mathrm{b}}$ \\
\hline Endoscopy_non CR & $7(58.3)$ & $12(85.7)$ & \\
\hline Endoscopy_CR and endoscopy_near CR & $5(41.7)$ & $2(14.3)$ & \\
\hline MR TRG & & & $0.683^{b}$ \\
\hline Grade I and II & $7(58.3)$ & $10(71.4)$ & \\
\hline Grade III-V & $5(41.7)$ & $4(28.6)$ & \\
\hline \multicolumn{4}{|l|}{ MR Tumor volume, $\mathrm{cm}^{3}$} \\
\hline Pre-CRT & $17.2 \pm 10.0^{\mathrm{a}}$ & $25.6 \pm 14.1^{\mathrm{a}}$ & 0.098 \\
\hline Post-CRT & $6.9 \pm 5.4^{\mathrm{a}}$ & $8.6 \pm 6.0^{\mathrm{a}}$ & 0.467 \\
\hline TVRR, \% & $62.4 \pm 20.9^{\mathrm{a}}$ & $66.1 \pm 14.3^{\mathrm{a}}$ & 0.603 \\
\hline MR DWI & & & $1.0^{\mathrm{b}}$ \\
\hline Negative & $4(33.3)$ & $4(28.6)$ & \\
\hline Equivocal and positive & $8(66.7)$ & $10(71.4)$ & \\
\hline
\end{tabular}

${ }^{a}$ Mean \pm standard deviation. ${ }^{b}$ Fisher's exact test. CEA, carcinoembryonic antigen; BMI, body mass index; T, tumor; N, node; pCR, pathologic complete response; CR, complete response; MR, magnetic resonance; TVRR, tumor volume reduction rate; CRT, chemoradiotherapy; TRG, tumor regression grade; DWI, diffusion weighted image; SD, standard deviation.

node regression grade (LRG) following preop-CRT was the only independent factor associated with relapse-free survival in patients with ypN-positive rectal cancer, who underwent preop-CRT. One of the interesting findings of this study was that the distribution of LRG was not associated with the TRG of the primary tumor, and that the LRG of each metastatic lymph node differed from the other within the same patient. These findings meant that the effects of radiation could differ between the primary tumor and metastatic lymph nodes. These discrepancies may be a possible reason for the different prediction powers of primary tumor cells and lymph node positivity in the cytotoxicity assays described in the present study. However, there was no ypN positivity in patients with
ypT0; thus, considering the relatively low rate of ypN-positive results in patients with ypT0 in a previous study (2), further large-scale investigation may be required to elucidate the true mechanisms underlying the observations of the present study.

The cytotoxicity assay, following 3D cell culture and radiation, had certain advantages. Firstly, the 7-day turnaround time for this procedure was acceptable, as long turnaround times could hinder clinical decision-making. Secondly, the assay can predict patients' tumor response before initiating preop-CRT. Although preop-CRT decreased the local recurrence rate more than postoperative adjuvant CRT, overall survival gain was not anticipated. Rather, preop-CRT may be associated with delayed adverse effects on long-term anorectal, sexual and 
Table VI. Univariate and multivariate analysis of factors associated with yp node positivity.

\begin{tabular}{|c|c|c|c|c|c|}
\hline \multirow[b]{2}{*}{ Parameters } & \multicolumn{3}{|c|}{ Univariate analysis } & \multicolumn{2}{|c|}{ Multivariate analysis } \\
\hline & $\mathrm{N}$ & $\mathrm{N}(\%)$ & P-value & OR $(95 \% \mathrm{CI})$ & P-value \\
\hline Sex & & & $>0.999^{\mathrm{a}}$ & & \\
\hline Male & 14 & $4(28.6)$ & & & \\
\hline Female & 12 & $3(25)$ & & & \\
\hline Age, years & & & $0.278^{\mathrm{a}}$ & & \\
\hline$<65$ & 21 & $7(33.3)$ & & & \\
\hline$\geq 65$ & 5 & 0 & & & \\
\hline $\mathrm{cT}$ & & & $>0.999^{\mathrm{a}}$ & & \\
\hline $\mathrm{T} 3$ & 23 & $6(26.1)$ & & & \\
\hline $\mathrm{T} 4$ & 3 & $1(33.3)$ & & & \\
\hline $\mathrm{cN}$ & & & $>0.999^{\mathrm{a}}$ & & \\
\hline Node negative & 2 & 0 & & & \\
\hline Node positive & 24 & $7(29.2)$ & & & \\
\hline Endoscopy grade & & & $0.629^{\mathrm{a}}$ & & \\
\hline Endoscopy_non-CR & 19 & $6(31.6)$ & & & \\
\hline Endoscopy_CR and endoscopy_near CR & 7 & $1(14.3)$ & & & \\
\hline MR TRG & & & $0.661^{\mathrm{a}}$ & & \\
\hline Grade I and II & 9 & $3(33.3)$ & & & \\
\hline Grade III-V & 17 & $4(23.5)$ & & & \\
\hline MR TVRR (\%) & & & $0.540^{\mathrm{a}}$ & & \\
\hline$<83.6$ & 23 & $7(30.4)$ & & & \\
\hline$\geq 83.6$ & 3 & 0 & & & \\
\hline MR DWI & & & $0.375^{\mathrm{a}}$ & & \\
\hline Negative & 8 & $1(12.5)$ & & & \\
\hline Equivocal and positive & 18 & $6(33.3)$ & & & \\
\hline 3D morphologic classification & & & $0.057^{\mathrm{a}}$ & & \\
\hline 'Mass-forming group' & 19 & $3(15.8)$ & & & \\
\hline 'None group' & 7 & $4(57.1)$ & & & \\
\hline Cytotoxicity assay & & & $0.026^{\mathrm{a}}$ & & 0.031 \\
\hline High $(>45)$ & 14 & $1(7.1)$ & & 1 & \\
\hline Low $(\leq 45)$ & 12 & $6(50)$ & & $13(1.2-133.2)$ & \\
\hline
\end{tabular}

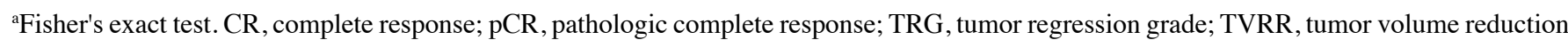
rate; DWI, diffusion weighted image; $\mathrm{MR}$, magnetic resonance; $\mathrm{T}$, tumor; $\mathrm{N}$, node.

urinary dysfunction (34). In this regard, a study demonstrated the efficacy of initiating chemotherapy in conjugation with selective radiation treatments (35). One reason for employing this new approach is the speculation that radiation-induced complications may be decreased. Several tumor response assays currently used in practice were considered as response evaluation tools rather than prediction models. MRI-based tumor volumetric evaluation, DWI, MR TRG, endoscopy grading, delay of surgery and other variables can be evaluated post-preop-CRT; however, these cannot predict tumor response before initiating preop-CRT. In this regard, the cytotoxicity assay may be useful for predicting whether a patient should undergo preop-CRT, although the actual clinical benefits should be evaluated with further investigations.
Nevertheless, there were several potential limitations of the present study. Immediate storage of fresh tissue in $25-\mathrm{cm}^{2}$ flasks, filled with RPMI culture medium supplemented with $1 \%$ penicillin-streptomycin is mandatory for the analysis. Although board-certified surgeons performed the pre-treatment biopsies, it is not always possible to obtain adequate tissue using rigid sigmoidoscopy. Another limitation was cell contamination during the cell culture process. It is well known that the intestinal and feces flora is mostly composed of obligate anaerobes such as Bacteroides and Bifidobacterium, and the accompanying bacteria during the biopsy process may contaminate the culture. The failure rate, due to cell contamination, cannot be ignored in the present study, which may hinder this procedure and therefore, a modified protocol is required to overcome this issue. 
The main limitation of the present study was its small sample size. In a previous study concerned with permeability, based on the spheroid 'round'-type morphological characteristic, increased resistance to drug therapy was observed compared with 'aggregate', 'mass' or 'none' types, which was associated with the Janus kinase-STAT signaling pathway (19). However, in the present study, the 'mass', 'aggregate' and 'round' types were grouped into the 'mass-forming' group, as the mean cytotoxicity level following radiation was similar among the 'round', 'mass' and 'aggregate' types. Although the response of the 3D spheroids to radiation treatment may be entirely different from the response to chemotherapy, the limited number of enrolled patients may hinder the detailed comparison. There are potential differences according to the definitions of ypT stage and TRG. Even with the same ypT3, some patients had small islets of viable cancer cells scattered in the subserosa layer that showed predominant fibrosis (good TRG), whereas other patients have ypT3 tumors in which most cancer cells remain viable (poor TRG) (36). Due to the small sample size in the present study, whether the differences in TRG of the same ypT stage were associated with the cytotoxicity assay could not be analyzed. Finally, it was also possible that the cytotoxicity assay may not accurately reflect humans' resistance to radiation and it does not accurately reproduce the surrounding environments of patients with rectal cancer. This needs to be validated in further studies.

In conclusion, a cytotoxicity assay following 3D cell culture and radiation predicted ypN positivity in patients with locally advanced rectal cancer that underwent preop-CRT. The preliminary findings of the present study may be useful in conducting further studies on this matter, which can potentially lead to clinical application in decision-making prior to initiating preoperative chemoradiotherapy.

\section{Acknowledgements}

The authors would like to thank Ms. Gamseoyun Lee (Severance Hospital, Yonsei University College of Medicine) for the support with patients' enrollment during the study.

\section{Funding}

No funding was received.

\section{Availability of data and materials}

The datasets used and/or analyzed during the present study are available from the corresponding author on reasonable request.

\section{Authors' contributions}

JKa provided the concept and idea of this study, analyzed and interpreted the experimental and patients' clinical data, and was a major contributor in writing the manuscript. MCP, $\mathrm{JKi}, \mathrm{HH}, \mathrm{BSM}, \mathrm{SHB}, \mathrm{KYL}$ and NKK participated in the data acquisition. NKK provided the concept and idea of the present study and revised the manuscript. All authors read and approved the final manuscript.

\section{Ethics approval and consent to participate}

The protocol of the present study was approved by the institutional review board of the Severance Hospital, Yonsei University College of Medicine (Seoul, Republic of Korea) (approval no. 4-2011-0445). Written informed consent was obtained from all participants.

\section{Patient consent for publication}

Not applicable.

\section{Competing interests}

The authors declare that they have no competing interests.

\section{References}

1. Sauer R, Becker H, Hohenberger W, Rödel C, Wittekind C, Fietkau R, Martus P, Tschmelitsch J, Hager E, Hess CF, et al: Preoperative versus postoperative chemoradiotherapy for rectal cancer. N Engl J Med 351: 1731-1740, 2004.

2. Yeo SG, Kim DY, Kim TH, Chang HJ, Oh JH, Park W, Choi DH, Nam H, Kim JS, Cho MJ, et al: Pathologic complete response of primary tumor following preoperative chemoradiotherapy for locally advanced rectal cancer: Long-term outcomes and prognostic significance of pathologic nodal status (KROG 09-01). Ann Surg 252: 998-1004, 2010.

3. Kim NK, Baik SH, Seong JS, Kim H, Roh JK, Lee KY, Sohn SK and $\mathrm{Cho} \mathrm{CH}$ : Oncologic outcomes after neoadjuvant chemoradiation followed by curative resection with tumor-specific mesorectal excision for fixed locally advanced rectal cancer: Impact of postirradiated pathologic downstaging on local recurrence and survival. Ann Surg 244: 1024-1030, 2006.

4. Zorcolo L, Rosman AS, Restivo A, Pisano M, Nigri GR, Fancellu A and Melis M: Complete pathologic response after combined modality treatment for rectal cancer and long-term survival: A meta-analysis. Ann Surg Oncol 19: 2822-2832, 2012.

5. Kim NK and Hur H: New Perspectives on predictive biomarkers of tumor response and their clinical application in preoperative chemoradiation therapy for rectal cancer. Yonsei Med J 56: 1461-1477, 2015.

6. Ryan JE, Warrier SK, Lynch AC, Ramsay RG, Phillips WA and Heriot AG: Predicting pathological complete response to neoadjuvant chemoradiotherapy in locally advanced rectal cancer: A systematic review. Colorectal Dis 18: 234-246, 2016.

7. Stijns RCH, Tromp MR, Hugen N and de Wilt JHW: Advances in organ preserving strategies in rectal cancer patients. Eur J Surg Oncol 44: 209-219, 2018.

8. Li J, Li L, Yang L, Yuan J, Lv B, Yao Y and Xing S: Wait-and-see treatment strategies for rectal cancer patients with clinical complete response after neoadjuvant chemoradiotherapy: A systematic review and meta-analysis. Oncotarget 7: 44857-44870, 2016.

9. Chang GJ, Rodriguez-Bigas MA, Eng C and Skibber JM: Lymph node status after neoadjuvant radiotherapy for rectal cancer is a biologic predictor of outcome. Cancer 115: 5432-5440, 2009.

10. Duchalais E, Glyn Mullaney T, Spears GM, Kelley SR, Mathis K, Harmsen WS and Larson DW: Prognostic value of pathological node status after neoadjuvant radiotherapy for rectal cancer. $\mathrm{Br}$ J Surg 105: 1501-1509, 2018.

11. Swellengrebel HA, Bosch SL, Cats A, Vincent AD, Dewit LG, Verwaal VJ, Nagtegaal ID and Marijnen CA: Tumour regression grading after chemoradiotherapy for locally advanced rectal cancer: A near pathologic complete response does not translate into good clinical outcome. Radiother Oncol 112: 44-51, 2014.

12. Jwa E, Kim JH, Han S, Park JH, Lim SB, Kim JC, Hong YS, Kim TW and Yu CS: Nomogram to predict ypN status after chemoradiation in patients with locally advanced rectal cancer. Br J Cancer 111: 249-254, 2014.

13. Newton AD, Li J, Jeganathan AN, Mahmoud NN, Epstein AJ and Paulson EC: A nomogram to predict lymph node positivity following neoadjuvant chemoradiation in locally advanced rectal cancer. Dis Colon Rectum 59: 710-717, 2016. 
14. von den Grün JM, Hartmann A, Fietkau R, Ghadimi M, Liersch T, Hohenberger W, Weitz J, Sauer R, Wittekind C, Ströbel P, et al: Can clinicopathological parameters predict for lymph node metastases in ypT0-2 rectal carcinoma? Results of the CAO/ARO/AIO-94 and CAO/ARO/AIO-04 phase 3 trials. Radiother Oncol 128: 557-563, 2018.

15. Pomerri F, Pucciarelli S, Maretto I, Zandoná M, Del Bianco P, Amadio L, Rugge M, Nitti D and Muzzio PC: Prospective assessment of imaging after preoperative chemoradiotherapy for rectal cancer. Surgery 149: 56-64, 2011.

16. Ryu KH, Kim SH, Yoon JH, Lee Y, Paik JH, Lim YJ and Lee KH: Diffusion-weighted imaging for evaluating lymph node eradication after neoadjuvant chemoradiation therapy in locally advanced rectal cancer. Acta Radiol 57: 133-141, 2016.

17. Antoni D, Burckel H, Josset $E$ and Noel G: Three-dimensional cell culture: A breakthrough in vivo. Int J Mol Sci 16: 5517-5527, 2015.

18. Gupta N, Liu JR, Patel B, Solomon DE, Vaidya B and Gupta V: Microfluidics-based 3D cell culture models: Utility in novel drug discovery and delivery research. Bioeng Transl Med 1: 63-81, 2016.

19. Park MC, Jeong H, Son SH, Kim Y, Han D, Goughnour PC Kang T, Kwon NH, Moon HE, Paek SH, et al: Novel morphologic and genetic analysis of cancer cells in a 3D microenvironment identifies STAT3 as a regulator of tumor permeability barrier function. Cancer Res 76: 1044-1054, 2016.

20. Zschenker O, Streichert T, Hehlgans S and Cordes N: Genome-wide gene expression analysis in cancer cells reveals $3 \mathrm{D}$ growth to affect ECM and processes associated with cell adhesion but not DNA repair. PLoS One 7: e34279, 2012.

21. Storch K, Eke I, Borgmann K, Krause M, Richter C, Becker K, Schröck E and Cordes N: Three-dimensional cell growth confers radioresistance by chromatin density modification. Cancer Res 70: 3925-3934, 2010.

22. Amin MB, Edge S, Greene F, Byrd DR, Brookland RK, Washington MK, Gershenwald JE, Compton CC, Hess KR, Sullivan DC, et al: AJCC cancer staging manual. 8th edition. Springer, New York, 2017.

23. Kang JH, Kim YC, Kim H, Kim YW, Hur H, Kim JS, Min BS Kim H, Lim JS, Seong J, et al: Tumor volume changes assessed by three-dimensional magnetic resonance volumetry in rectal cancer patients after preoperative chemoradiation: The impact of the volume reduction ratio on the prediction of pathologic complete response. Int J Radiat Oncol Biol Phys 76: 1018-1025, 2010.

24. Han YD, Kim WR, Park SW, Cho MS, Hur H, Min BS, Baik SH Lee KY and Kim NK: Predictors of pathologic complete response in rectal cancer patients undergoing total mesorectal excision after preoperative chemoradiation. Medicine (Baltimore) 94: e1971, 2015.

25. Kim H, Myoung S, Koom WS, Kim NK, Kim MJ, Ahn JB, Hur H and Lim JS: MRI risk stratification for tumor relapse in rectal cancer achieving pathological complete remission after neoadjuvant chemoradiation therapy and curative resection. PLoS One 11: e0146235, 2016.
26. An C, Huh H, Han KH, Kim MJ, Kim NK, Kim H and Lim JS: Use of preoperative MRI to select candidates for local excision of MRI-Staged T1 and T2 rectal cancer: Can MRI select patients with N0 tumors? Dis Colon Rectum 58: 923-930, 2015.

27. Mandard AM,DalibardF, Mandard JC, Marnay J, Henry-Amar M, Petiot JF, Roussel A, Jacob JH, Segol P, Samama G, et al: Pathologic assessment of tumor regression after preoperative chemoradiotherapy of esophageal carcinoma. Clinicopathologic correlations. Cancer 73: 2680-2686, 1994.

28. Garcia-Aguilar J, Renfro LA, Chow OS, Shi Q, Carrero XW, Lynn PB, Thomas CR Jr, Chan E, Cataldo PA, Marcet JE, et al: Organ preservation for clinical T2N0 distal rectal cancer using neoadjuvant chemoradiotherapy and local excision (ACOSOG Z6041): Results of an open-label, single-arm, multi-institutional, phase 2 trial. Lancet Oncol 16: 1537-1546, 2015.

29. Renehan AG, Malcomson L, Emsley R, Gollins S, Maw A, Myint AS, Rooney PS, Susnerwala S, Blower A, Saunders MP, et al: Watch-and-wait approach versus surgical resection after chemoradiotherapy for patients with rectal cancer (the OnCoRe project): A propensity-score matched cohort analysis. Lancet Oncol 17: 174-183, 2016.

30. De Nardi P and Carvello M: How reliable is current imaging in restaging rectal cancer after neoadjuvant therapy? World J Gastroenterol 19: 5964-5972, 2013

31. Kim DW, Kim DY, Kim TH, Jung KH, Chang HJ, Sohn DK, Lim SB, Choi HS, Jeong SY and Park JG: Is T classification still correlated with lymph node status after preoperative chemoradiotherapy for rectal cancer? Cancer 106: 1694-1700, 2006

32. Read TE, Andujar JE, Caushaj PF, Johnston DR, Dietz DW, Myerson RJ, Fleshman JW, Birnbaum EH, Mutch MG and Kodner IJ: Neoadjuvant therapy for rectal cancer: Histologic response of the primary tumor predicts nodal status. Dis Colon Rectum 47: 825-831, 2004.

33. Choi JP, Kim SJ, Park IJ, Hong SM, Lee JL, Yoon YS, Kim CW, Lim SB, Lee JB, Yu CS and Kim JC: Is the pathological regression level of metastatic lymph nodes associated with oncologic outcomes following preoperative chemoradiotherapy in rectal cancer? Oncotarget 8: 10375-10384, 2017.

34. Loos M, Quentmeier P, Schuster T, Nitsche U, Gertler R, Keerl A, Kocher T, Friess H and Rosenberg R: Effect of preoperative radio(chemo)therapy on long-term functional outcome in rectal cancer patients: A systematic review and meta-analysis. Ann Surg Oncol 20: 1816-1828, 2013.

35. Schrag D, Weiser MR, Goodman KA, Gonen M, Hollywood E, Cercek A, Reidy-Lagunes DL, Gollub MJ, Shia J, Guillem JG, et al: Neoadjuvant chemotherapy without routine use of radiation therapy for patients with locally advanced rectal cancer: A pilot trial. J Clin Oncol 32: 513-518, 2014

36. Min BS, Kim NK, Pyo JY, Kim H, Seong J, Keum KC, Sohn SK and $\mathrm{Cho} \mathrm{CH}$ : Clinical impact of tumor regression grade after preoperative chemoradiation for locally advanced rectal cancer: Subset analyses in lymph node negative patients. J Korean Soc Coloproctol 27: 31-40, 2011. 